\title{
DETERMINAÇÃO DE CONDIÇÕES ÓTIMAS PARA A REAÇÃO DE TRANSESTERIFICAÇÃO DO ÓLEO DE CANOLA REFINADO
}

\author{
R. T. KIFFER ${ }^{1}$, P. A. ARROYO ${ }^{1}$ \\ ${ }^{1}$ Universidade Estadual de Maringá, Departamento de Engenharia Química \\ E-mail para contato: kiffer.renata@hotmail.com/arroyo@deq.uem.br
}

\begin{abstract}
RESUMO - Ésteres de ácidos graxos de metila ou etila, obtidos a partir de óleos vegetais, mostraram grande potencialde utilização, contribuindo efetivamente para a matriz de combustíveis para transporte. O objetivo deste trabalho foi determinar as condições ótimas dos parâmetros temperatura $\left(30-70{ }^{\circ} \mathrm{C}\right)$, razão molar óleo:álcool (1:3-1:12) e tipo de álcool (metanol, etanol, propanol e butanol ) para a reação de transesterificação de óleo de canola refinado. Verificou-se que o óleo de canola possui elevado teor em ácidos graxos insaturados (93,9\%), sendo os principais o palmítico, o oléico, o linoléico e o $\alpha$-linolênico. A rota etílica apresentou o melhor desempenho, a $60{ }^{\circ} \mathrm{C}$ e razão molar óleo:álcool de 1:6, com rendimento médio em ésteres de $95,2 \%$ e máximo de $97,8 \%$. Os parâmetros de qualidade, conforme normas da ANP, foram CFPP $-7^{\circ} \mathrm{C}$, número de cetano $60,9 \mathrm{e}$ estabilidade à oxidação de 9,3 h, que confirmam a qualidade do biodiesel obtido.
\end{abstract}

Palavras-chave: etanol, canola, ácidos graxos, transesterificação, CFPP, estabilidade, cetano

\section{INTRODUÇÃO}

O biodiesel, um combustível Diesel alternativo, é obtido a partir de fontes renováveis, tais como óleos vegetais e gorduras animais. Este combustível é biodegradável e não-tóxico e tem um perfil baixo de emissão em comparação com o diesel de petróleo. Segundo Feres (2010), o uso de biodiesel permitirá um equilíbrio entre a agricultura, desenvolvimento econômico e ambiente. A adição de biodiesel ao diesel mineral, nas mais diversas percentagens, é a estratégia utilizada para, paulatinamente, substituir a queima do combustível fóssil ou, pelo menos, minimizar o impacto de seu uso no ambiente.

Em função da importância do biodiesel e da futura regulamentação para sua utilização no Brasil, o estabelecimento de padrões de qualidade para o biodiesel se constitui num fator primordial para sua adoção ser realizada com sucesso. Neste cenário, a busca por fontes alternativas de oleaginosas para a produção de biodiesel no Brasil, que atendam às normas estabelecidas pela Agência Nacional do Petróleo, Gás Natural e Biocombustíveis (ANP), é de grande importância, uma vez que o biodiesel obtido a partir do óleo de soja não atende a todas as normas vigentes, necessitando da adição de antioxidantes para que isso ocorra. Estas características limitam também a exportação do biodiesel de soja, principalmente, para o grande mercado europeu. 
Uma das alternativas de cultura oleaginosa que pode contribuir para a matriz brasileira é a canola (Brassicanapus L. e Brassica rapa L.) obtida pelo melhoramento genético da colza, possui rendimento em óleo maior que outras variedades, com uma média de 34 e $40 \%$, ou seja, mais que 2 vezes o rendimento em óleo da soja (Milazzo et al., 2013).

Portanto, o objetivo deste trabalho foi determinar as condições ótimas dos parâmetros temperatura (30-70 $\left.{ }^{\circ} \mathrm{C}\right)$, razão molar óleo:álcool (1:3-1:12) e tipo de álcool (metanol, etanol, propanol e butanol ) para a reação de transesterificação de óleo de canola refinado.

\section{MATERIAIS E MÉTODOS}

\subsection{Matéria-prima}

O estudo deste trabalho foi direcionado para a produção de ésteres por meio do óleo de canola refinado. Os reagentes utilizados na reação de transesterificação foram os álcoois:etanol anidro $(99,8 \%)$, metanol $(99,8 \%)$, propanol $(99,5 \%)$, butanol $(99,5 \%)$ e o catalisador metilato de sódio (30\%).

\subsection{Caracterização do Óleo}

Para o óleo de canola refinado, pesaram-se $100 \mathrm{mg}$ de amostra em um tubo de ensaio, e depois de derivatizado, adicionaram-se $2 \mathrm{~mL}$ de $\mathrm{n}$-heptano, agitando-se o frasco até solubilização total da matéria graxa. Em seguida, foram adicionados $2 \mathrm{~mL}$ da solução $2 \mathrm{~mol} / \mathrm{L}$ de $\mathrm{KOH}$ em metanol e a mistura foi agitada novamente por cerca de 5 minutos, após separação o sobrenadante foi utilizado para injeção no cromatógrado a gás Varian, modelo CP - 3800, com detector de ionização em chama (DIC), contendo uma coluna capilar específica para separação de ácidos graxos (BP - X70 - SGE) de $30 \mathrm{~m}$ x 0,25 mm. O gás de arraste utilizado foi o Hélio, numa razão split de 1:10. A análise foi realizada com programação de temperatura da coluna, iniciada a $110{ }^{\circ} \mathrm{C}$, sendo aquecida até $250{ }^{\circ} \mathrm{C}$ a $5{ }^{\circ} \mathrm{C} / \mathrm{min}$. A temperatura do detector foi mantida em $220{ }^{\circ} \mathrm{C}$ e do injetor em $260{ }^{\circ} \mathrm{C}$. A identificação dos picos dos ácidos graxos foi realizada por comparação com os tempos de retenção de uma mistura de padrões de éster metílicos de ácidos graxos (Sulpeco TM37 FAME Mix, Sulpeco, Inc., Belleefonte, PA).

\subsection{Síntese dos Ésteres}

As reações de transesterificação foram realizadas pesando-se $100 \mathrm{~g}$ de óleo de canola em um balão de três bocas, sendo levado a um banho termostático com controle de temperatura $\left(60{ }^{\circ} \mathrm{C}\right)$, sob agitação $(800 \mathrm{rpm})$. Pesou-se o catalisador (solução $30 \%$ de metilato de sódio), na concentração de $1 \%$ em relação à massa de óleo e o álcool (metanol, etanol, propanol e butanol). Para cada teste foram preparados doze tubos de ensaio para amostragem, nos tempos de $1,2,3,5,10,15,20,30,45,60,90$ e 180 minutos, contendo $5 \mathrm{~mL}$ da solução de ácido clorídrico 0,1 mol/L, mantido sob refrigeração. 
Os parâmetros de reações utilizados tiveram como base as condições ótimas consideradas na literatura para a produção do biodiesel a partir do óleo de canola refinado (Silva et al., 2011) demonstraram que a razão molar entre o óleo e o álcool e a temperatura são as variáveis que mais influenciam a transesterificação dos óleos de soja e canola para a produção de biodiesel. Por este motivo escolheu-se estudar os parâmetros, tipo de álcool, temperatura, e razão molar.A determinação quantitativa do rendimento de ésteres no biodiesel foi realizada por cromatografia gasosa, utilizando-se o método EN 14103 e a caracterização conforme normas ANP (2012).

\section{RESULTADOS E DISCUSSÃO}

\subsection{Caracterização do Óleo}

Os valores encontrados para a composição química em ácidos graxos do óleo de canola, conforme mostrado na Tabela 1, foram semelhantes aos descritos por Anvisa (1999), Siemens e Daun (2005) e Kulkani et al. (2007). O óleo também apresentou elevado teor de ácidos graxos insaturados, 93,9\%, sendo a composição química baseada principalmente nos ácidos palmítico $(\mathrm{C} 16: 0,4,34 \%)$, oléico $(\mathrm{C} 18: 1,66,3 \%)$, linoléico $(\mathrm{C} 18: 2,17 \%)$ e $\alpha$ linolênico (C18:3, 8,9\%). Esta composição de óleo é adequada para a produção de biodiesel, principalmente, levando em consideração as características de qualidade como CFPP, número de cetano e estabilidade, são de grande relevância para atendimento do mercado nacional e internacional(Siemens e Daun, 2005; Kulkani et al., 2007; Omidi et al., 2010).

Tabela 1- Composição em ácidos graxos do óleo de canola refinado.

\begin{tabular}{ccc}
\hline Ácido Graxo & Tempo de retenção (min) & \% mássica média \\
\hline mirístico (C14:0) & 14,54 & $<0,1$ \\
palmítico (C16:0) & 17,47 & 4,3 \\
palmitoléico (C16:1) & 18,04 & 0,4 \\
esteárico (C18:0) & 20,07 & 0,2 \\
oléico (C18:1) & 20,93 & 66,3 \\
linoléico (C18:2) & 21,89 & 17 \\
$\alpha$-linolênico (C18:3) & 22,79 & 8,9 \\
araquídico (C20:0) & 23,89 & $<0,1$ \\
eicosenóico (C20:1) & 24,43 & 1,1 \\
behênico (22:0) & 26,90 & 0,4 \\
lignocérico (C24:0) & 29,72 & 0,2 \\
tetracosenóico (C24:1) & 30,21 & $<0,2$ \\
Docosahexaenóico (C22:6) & 31,7 & $<0,2$ \\
\hline
\end{tabular}




\subsection{Transesterificação do Óleo de Canola Refinado}

Para o estudo da transesterificação do óleo de canola refinado foi analisada primeiramente a influência do tipo de álcool, sendo em seguida analisada a influência dos parâmetros de temperatura e razão molar óleo:álcool no rendimentos em ésteres, e, fixado velocidade de agitação, tipo e quantidade de catalisador.

\section{Influência do tipo de álcool}

A primeira etapa do estudo foi determinar a influência do tipo de álcool no rendimento em ésteres em função do tempo de reação para o óleo de canola refinado. Deste modo, utilizou-se uma razão molar óleo:álcool de 1:6 (Vicente et al., 2004; Meher et al., 2006), utilizando-se $\mathrm{CH}_{3} \mathrm{ONa} 1 \%$ como catalisador, na temperatura de $60{ }^{\circ} \mathrm{C}$. O objetivo foi realizar um estudo comparativo da utilização do metanol, etanol, butanol e propanol como agentes esterificantes, uma vez que o metanol é largamente utilizado na indústria do biodiesel (Knothe et al., 2005; Baiju et al., 2009). Porém, o carbono adicional trazido pela molécula de etanol aumenta ligeiramente a quantidade de calor e o número de cetano do biodiesel produzido.

O propanol e butanol são considerados também álcoois de baixa massa molar e podem ser utilizados na transesterificação (Schuchardt et al., 1998), embora o preço e a disponibilidade no mercado possam ter impacto negativo em seu uso.

As curvas cinéticas apresentadas na Figura 1 mostram que a reação ocorre mais rapidamente quando o metanol foi utilizado, pois nos primeiros 5 minutos a reação atingiu a condição de equilíbrio, provavelmente, devido a sua reatividade superior (Baiju et al., 2009). Para o etanol a condição de equilíbrio foi atingida após 15 minutos de reação, provavelmente devido a sua menor reatividade quando comparada com o metanol. Para o propanol e o butanol o comportamento foi semelhante ao etanol e o equilíbrio também foi atingido a partir dos 15 minutos de reação.

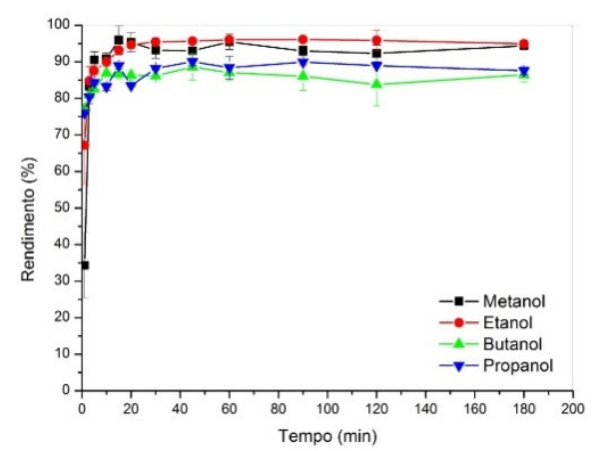

Figura 1 - Variação do rendimento em ésteres em função do tempo, para diferentes tipos de álcool, com a reação realizada a 60

${ }^{\circ} \mathrm{C}, 1 \%$ de $\mathrm{CH}_{3} \mathrm{ONa}$, razão molar óleo:álcool de1:6 e 800 rpm.

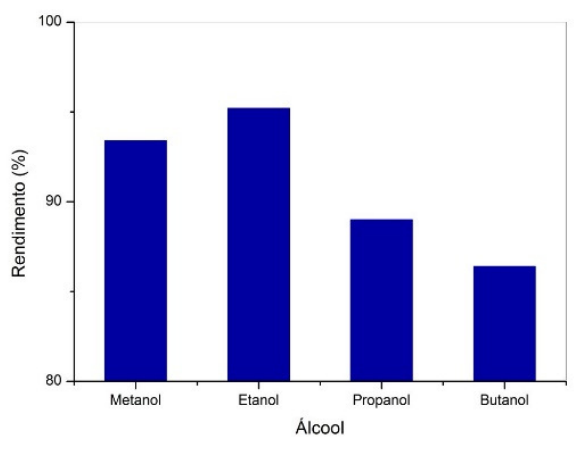

Figura 2 - Rendimento máximo médio em ésteres em função do tipo de álcool, para a reação a $60{ }^{\circ} \mathrm{C}, 1 \%$ de $\mathrm{CH}_{3} \mathrm{ONa}$, razão molar óleo:álcool de1:6 e 800 rpm. 
Para uma visualização melhor da influência dos diferentes álcoois sobre a transesterificação do óleo de canola refinado a Figura 2 mostra o rendimento em ésteres em função do tipo de álcool estudado. Desta forma, tendo em vista os resultados obtidos pelos diferentes álcoois, para o estudo da influência dos demais parâmetros sobre rendimento em ésteres na reação de transesterificação do óleo de canola foi utilizado o etanol como agente esterificante.

\section{Influência da temperatura}

As Figuras 3 e 4 mostram as curvas de rendimento em ésteres em função da temperatura, para a reação de transesterificação do óleo de canola refinado realizada com $1 \%$ de $\mathrm{CH}_{3} \mathrm{ONa}$, razão molar óleo:álcool de 1:6 e $800 \mathrm{rpm}$. Pelas curvas cinéticas apresentadas pode-se verificar que o aumento na temperatura de $30{ }^{\circ} \mathrm{C}$ para $60{ }^{\circ} \mathrm{C}$ acarreta um aumento da velocidade de reação, pois a condição de equilíbrio no meio reacional é alcançada em tempos de reação mais curtos (Baiju et al.; 2009; Georgogianni et al., 2009).

Além disso, observa-se também um aumento no rendimento em ésteres com a temperatura neste intervalo. $\mathrm{O}$ aumento de temperatura de 60 para $70{ }^{\circ} \mathrm{C}$ não afeta de forma significativa o tempo para se atingir a condição de equilíbrio, embora seja verificada uma diminuição no rendimento máximo em ésteres, conforme mostra a Figura 4. Tal fato pode ser devido a uma menor quantidade de álcool presente na fase líquida em relação à condição de $60{ }^{\circ} \mathrm{C}$, pois a temperatura de ebulição do álcool etílico é próxima a $70{ }^{\circ} \mathrm{C}$, o que poderia levar a uma maior evaporação deste e, consequentemente, uma quantidade maior de álcool estaria presente na fase gasosa e em menor contato com os reagentes presentes na fase líquida, o que pode variar com o tempo devido à própria reação de consumo de etanol da fase líquida.

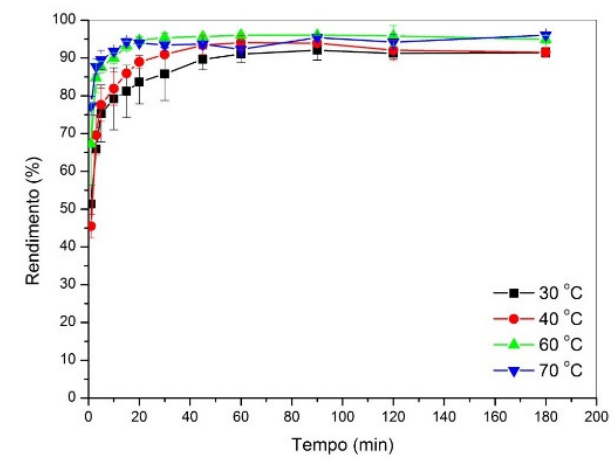

Figura 3 - Rendimento em ésteres em função da temperatura, para a reação realizada com $1 \%$ de $\mathrm{CH} 3 \mathrm{ONa}$, razão molar óleo:álcool de 1:6 e 800 rpm.

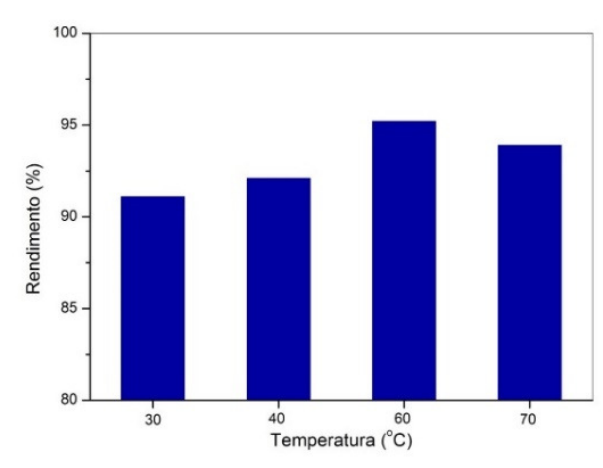

Figura 4 - Rendimento máximo médio em função da temperatura, para a reação realizada com $1 \% \mathrm{CH} 3 \mathrm{ONa}$, razão molar óleo:álcool de 1:6 e 800 rpm.

Influência da razão molar 
No estudo da influência da razão molar óleo:álcool (1:6, 1:7,5, 1:9 e 1:12) na reação de transesterificação de óleo de canola refinado com etanol utilizou-se como catalisador $1 \%$ de $\mathrm{CH}_{3} \mathrm{ONa}$, temperatura de $60{ }^{\circ} \mathrm{C}$ e velocidade de agitação de $800 \mathrm{rpm}$.

As curvas cinéticas apresentadas na Figura 5 e 6 indicam uma influência significativa da razão molar óleo:álcool sobre o rendimento em ésteres. Desta maneira, verifica-se que o aumento da quantidade de álcool, na razão molar óleo:álcool de 1:3 (condição estequiométrica) para 1:6, favorece o deslocamento do equilíbrio da reação na direção dos produtos, acarretando aumento no rendimento em ésteres, embora ocorra um aumento no tempo necessário para que o equilíbrio no meio reacional seja atingido. Estes valores de rendimento em ésteres são semelhantes aos obtidos por Freedman et al. (1984) para a reação com óleo de canola na razão molar óleo:álcool de 1:6.

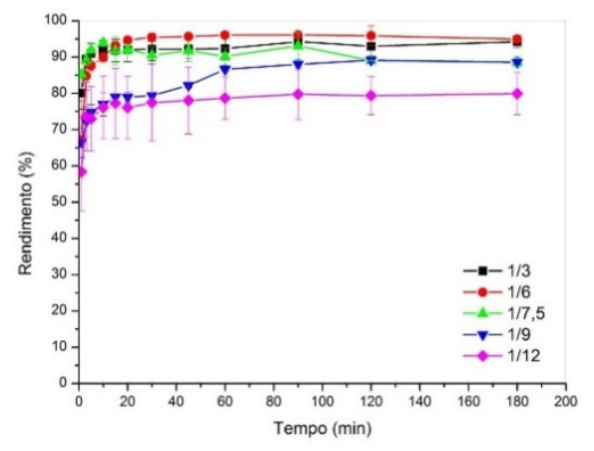

Figura 5 - Rendimento em ésteres em função da razão molar óleo:álcool, para a reação realizada a $60{ }^{\circ} \mathrm{C}, 1 \% \mathrm{CH}_{3} \mathrm{ONa}$ e $800 \mathrm{rpm}$.

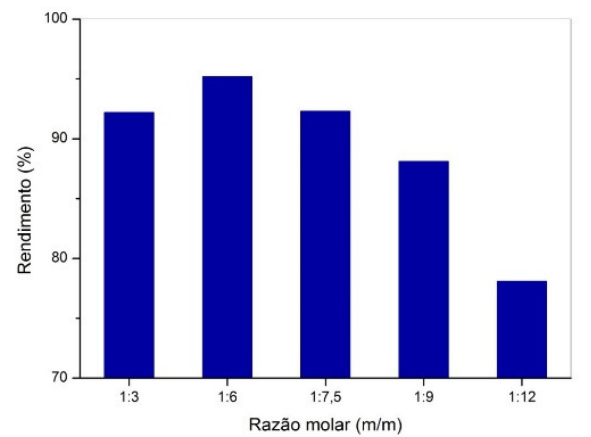

Figura 6 - Rendimento máximo médio em ésteres em função da razão molar óleo:álcool, para a reação realizada a $60^{\circ} \mathrm{C}, 1 \% \mathrm{CH}_{3} \mathrm{ONa}$ e $800 \mathrm{rpm}$.

Na Figura 5 também se pode verificar que a utilização de razões molares óleo:álcool mais altas do que 1:6 na reação de transesterificação levam a uma diminuição significativa no rendimento em ésteres. Comportamento semelhante também foi observado por Leung e Guo (2006), para razão molar 1:7,5, inclusive para a diminuição de rendimento em ésteres com o tempo de reação. Além disso, Vyaset al. (2009) relatou uma diminuição significativa do rendimento em ésteres, quando foram utilizadas razões molares óleo:álcool de 1:9 e 1:12. Uma hipótese a ser levada em consideração para justificar os resultados obtidos está relacionada ao efeito do etanol no meio reacional, quando presente em grandes quantidades. Assim, pode ser possível que tenha ocorrido uma grande emulsificação do óleo pelo etanol, levando até provavelmente a uma inversão de micelas, o que diminuiria a taxa de transferência de massa no meio, dificultando a reação de transesterificação.

A Figura 6 mostra o rendimento máximo médio em ésteres em função da razão molar óleo:álcool, ressaltando que para a razão molar óleo:álcool de 1:6 obtém-se o rendimento mais alto em ésteres, sendo esta a condição ótima de reação para o sistema estudado.O éster etílico obtido em condições ótimas, foi caracterizado conforme demonstradona Tabela 2. 
Tabela 2- Resultados de qualidade do éster etílico obtido a $60{ }^{\circ} \mathrm{C}, 1 \% \mathrm{CH}_{3} \mathrm{ONa}$, razão molar $1: 6$ e $800 \mathrm{rpm}$.

\begin{tabular}{|c|c|c|}
\hline Caracteristica & Unidade & Resultado \\
\hline Massa Específica a $20{ }^{\circ} \mathrm{C}$ & $\mathrm{kg} / \mathrm{m}^{3}$ & 875,1 \\
\hline Viscosidade Cinemática a $40{ }^{\circ} \mathrm{C}$ & $\mathrm{mm}^{2} / \mathrm{s}$ & 4,790 \\
\hline $\mathrm{CFPP}$ & ${ }^{\circ} \mathrm{C}$ & -7 \\
\hline Índice de acidez & $\mathrm{mg} \mathrm{KOH} / \mathrm{g}$ & 0,12 \\
\hline Estabilidade $110{ }^{\circ} \mathrm{C}$ & $\mathrm{h}$ & 9,3 \\
\hline Número de Cetano & - & 60,9 \\
\hline
\end{tabular}

Os resultados encontrados para as características analisadas estão de acordo com as especificações selecionadas de ASTM D6751, EN 14214 e ANP para padrões de combustível biodiesel. Os resultados das características analisadas podem estar relacionados com a composição dos ácidos graxos do óleo de canola refinado (Knothe et al., 2005; Siemens e Daun, 2005).

\section{CONCLUSÕES}

De maneira geral, o rendimento em ésteres aumenta rapidamente nos primeiros 5 minutos de reação, atingindo uma condição de equilíbrio em tempos relativamente curtos (15-45 minutos). $\mathrm{O}$ aumento da temperatura faz com que este equilíbrio seja alcançado em tempos menores.

A utilização de etanol para a transesterificação do óleo de canola levou a um aumento no rendimento em ésteres em relação à utilização de metanol, propanol e butanol, para a razão óleo:álcool de 1:6.

As condições ótimas de reação geraram um rendimento médio em ésteres etílicos de 95,2\% e máximo de 97,8\%, com características de CFPP $-7{ }^{\circ} \mathrm{C}$, número de cetano 60,9 e estabilidade de 9,3 h, que atendem às especificações nacionais (ANP) e internacionais (ASTM e EN).

\section{REFERÊNCIAS}

1. ANP - Agência Nacional do Petróleo, Gás Natural e Biocombustíveis. Resolução ANP N 14, de 11.5.2012 - DOU 18.5.2012

2. ANVISA - Agência Nacional de Vigilância Sanitária. Resolução Anvisa no 482, de 23 de setembro de 1999. 
3. BAIJU, B.; NAIK, M.K.; DAS, L. M. A comparative evaluation of compression ignition engine characteristics using methyl and ethyl esters of Karanja oil. Renewable. Energy, v. 34 p. 1616-1621, 2009.

4. CLARK, S.; WAGNER, J.L.; SCHRACK, M.D.; PIENNAR, J. P. Methyl and ethyl soybean esters as renewable fuels for diesel engines. Oil Chem. Soc., v. 61 p. 1632, 1998.

5. FERES, D. Os Biocombustíveis na matriz energética alemã: possibilidades de cooperação com o Brasil, 2010.

6.FREEDMAN, B.; PRYDE, E. H.; MOUNTS, T. L. Variables affecting the yield of fatty esters transesterified vegetable oils. J. Am. Oil Chem. Soc., v. 61, n. 10, p. 1638-1643, 1984.

7. GEORGOGIANNI, A. K.; KATSOULIDIS, P.J.; POMONIS, G.; MANOS, M.G. Transesterification of rapeseed oil for the production of biodiesel using homogeneous and heterogeneous catalysis. Fuel Processing Technology, v. 90, 1016 - 1022, 2009.

8. KNOTHE G.; BAGBY, M.O.; RYAN, T.W. Dependence of biodiesel fuel properties on the structure of fatty acid alkyl esters, Fuel Process Technol, v.86, p. 1059-70, 2005.

09. KULKARNI, M.; DALAI, A.K.; BAKHSHIN. Transesterification of canola oil in mixed methanol/ethanol system and use of esters as lubricity additive. Bioresource Technology, v. 98 p. 2027-2033, 2007.

10.MEHER, L. C.; DHARMAGADDA, V. S. S.; NAIK, S. N. Optimization of alkalicatalized transesterification of Pongamia pinnata oil for production of biodiesel. Bioresource Technology, v. 97, p. 1392-1397, 2006

11. MILAZZO, M.F; SPINA, F.; VINCI, A.; ESPRO, C.; BART. J. Brassica biodiesels: Past, present and future.Renewable and Sustainable, v.18 p. 350-389, 2013.

12. OMIDI, H.; TAHMASEBI, Z.; BADI, H. A.; TORABI, H.; MIRANSARI, M. Fatty acid composition of canola (Brassica napus L.), as affected by agronomical, genotypic and environmental parameters. C. R. Biologies, v. 333, p. 248-254, 2010.

13. SCHUCHARDT, U.; SERCHELI, R.; VARGAS, M. Transesterification of vegetable oils: a review. J. Braz. Chem. Soc., v. 9, p. 199-210, 1998.

14. SIEMENS, B.J and DAUN, J.K. Determination of the Fatty Acid Composition of Canola, Flax, and Solin by Near-Infrared Spectroscopy. JAOCS, v.82 p. 153-157, 2005.

15. SILVA, G. F.; CAMARGO, F. L.; FERREIRA, A.L.O. Applicationof response surfacemethodology for optimizationof biodiesel production by transesterification of soy bean oil with etanol. Fuel Processing Technology, v. 92, p. 407-413, 2011.

16. VICENTE, G.; MARTÍNEZ, M.; ARACIL. Integrated biodiesel production: acomparcion of differentehomogeneus catalysts systems. Bioresource Technology, v.92, p. 297-305, 2004.

17. VISENTAINER, J. V.; FRANCO, M. R. B. Ácidos Graxos em óleos e gorduras: identificação e quantificação. Ed. Varela, São Paulo, p. 120, 2006.

18. VYAS, A. P.; SUBRAHMANYAM, N.; PATEL, P. A. Production of biodiesel throught transesterification of Jatropha oil using $\mathrm{KNO}_{3} / \mathrm{Al}_{2} \mathrm{O}_{3}$. Fuel, 88, p. 625-628, 2009. 